\title{
Comparative Study Between Fiscal Poverty Alleviation and Financial Poverty Alleviation in Tibetan Areas of Sichuan Province
}

\author{
Yating $\mathrm{He}^{1, *}$ Shan Wang ${ }^{1}$ Lu Chen $^{1}$ Min Wei ${ }^{1}$ Panyue Zhang ${ }^{1}$
}

${ }^{1}$ School of Economics, Sichuan Agricultural University, Chengdu, Sichuan, China

"Corresponding author. Email: victoriahyt@foxmail.com

\begin{abstract}
In the post-poverty alleviation era, how to achieve sustainable poverty reduction is the most concerned issue. Therefore, adjusting the means of poverty alleviation is very important. Based on the data from 2014-2016 Statistical Yearbook of Tibetan Areas in Sichuan, this paper used the DEA-Malmquist (Data Envelopment Analysis-Malmquist) index model to measure the efficiency of fiscal and financial poverty alleviation in Aba and Ganzi prefectures. On the basis of whole, horizontal and vertical comparison, it can be found that the efficiency of fiscal and financial poverty alleviation in most counties is high, which shows that the poverty-alleviation policies in recent years have great effects. However, from any point of view, the efficiency of financial poverty alleviation is higher than that of fiscal poverty alleviation. Therefore, in the future, we should pay attention to the credit to achieve sustainable poverty reduction and income increase. In other words, we must improve the financial service system, innovate financial service products, and strive to achieve the match between credit supply and credit demand.
\end{abstract}

Keywords: fiscal poverty alleviation, financial poverty alleviation, DEA-Malmquist, Tibetan areas of Sichuan

Province

\section{INTRODUCTION}

In February 2020, Tibetan areas of Sichuan were declared to have been lifted out of poverty. In recent years, its poverty reduction mechanism mainly operates from two perspectives: fiscal poverty alleviation and financial poverty alleviation. On the one hand, the government promotes the development of people's livelihood in Tibetan areas through fiscal poverty-alleviation funds and tax preferential policies, the most typical of which are The Six Livelihood Projects in Tibetan Areas of Sichuan. In 2013, Sichuan Province started to implement The Six Livelihood Projects in Tibetan Areas of Sichuan, using fiscal poverty-alleviation funds to promote the development of Tibetans' livelihood: covering new housing construction, education revitalization, medical and health promotion, social security promotion, cultural prosperity, and poverty alleviation.

On the other hand, all financial institutions follow the policy to provide diversified financial services, and take microfinance as the main channel. The development of microfinance at home and abroad shows a trend of diversification and has become the main means of financial poverty alleviation in rural areas. For the clients of microfinance, the main role of financial services is to respond to economic opportunities, cope with difficulties and invest in the future. In Tibetan areas of Sichuan, there are three major services of microfinance, that is, small loan, small deposit and small insurance. Then, what is the efficiency of fiscal poverty alleviation and financial poverty alleviation? What is the relationship between them? Based on these questions, this paper will review the literature on fiscal poverty alleviation and financial poverty alleviation, test the actual situation of Tibetan areas in Sichuan. Thus, some suggestions can be put forward to promote the realization of sustainable poverty reduction in Tibetan areas.

\section{LITERATURE REVIEW}

At present, in the comparative studies between fiscal poverty alleviation and financial poverty alleviation, it can be shown that financial input and credit input can bring significant poverty alleviation effect. However, there is still some dispute about which one has higher effect. Wen[1] constructed an agricultural output model and analyzed the impact of fiscal input and financial support on agricultural output, but did not make a comparison. Jia[2] analyzed the income-increase effect of fiscal poverty alleviation and financial poverty alleviation from the village level. Shen[3], after analyzing the data of 22 provinces from 2014 to 2017, they constructed the DEA-Malmquist index model to compare the efficiency 
of fiscal poverty alleviation and financial poverty alleviation from multiple dimensions, and finally found that the efficiency of financial poverty alleviation was higher than that of fiscal poverty alleviation. $\mathrm{Wu}[4]$ conducted empirical tests using quantile regression, ordered Probit model and Tobit model, from the perspective of multi-dimensional poverty and poverty alleviation objects, found that the income-increase effect of fiscal poverty alleviation was better than that of financial poverty alleviation. However, for different poverty alleviation objects, the actual effects of the two were different.

In conclusion, there is an obvious dispute about the effects between fiscal poverty alleviation and financial poverty alleviation, and more cases are needed to provide support. Moreover, there are few studies analyzing the poverty alleviation situation in Tibetan areas. Therefore, this paper can further enrich the research cases in this field.

\section{EMPIRICAL ANALYSIS}

\section{A. The model}

Data envelopment analysis (DEA) is a widely used efficiency evaluation method. It does not need to set a specific function, so the errors caused by model setting are avoided. In existing studies, DEA are applied in various ways, including the static DEA model represented by CCR model (constant return to scale) and BCC model (variable return to scale), and the dynamic DEA model represented by DEA-Malmquist index model.

The DEA-Malmquist index model adopted in this paper is used for the linear programming analysis of panel data, and the productivity change is measured from two aspects of technical progress change (TECHCH) and comprehensive technical efficiency change (EFFCH). Farerr[5] defines a Malmquist index model based on output:

$$
\mathrm{m}_{0}\left(y_{t+1}, x_{t+1}, y_{t}, x_{t}\right)=\left[\frac{d_{0}^{t}\left(x_{t+1}, y_{t+1}\right)}{d_{0}^{t}\left(x_{t}, y_{t}\right)} \times \frac{d_{0}^{t+1}\left(x_{t+1}, y_{t+1}\right)}{d_{0}^{t+1}\left(x_{t}, y_{t}\right)}\right]^{1 / 2}
$$

Where, $\mathrm{m}_{0}\left(y_{t+1}, x_{t+1}, y_{t}, x_{t}\right)$ represents the productivity of the production point $\left(\mathrm{x}_{t+1}, y_{t+1}\right)$ compared with the production point $\left(\mathrm{x}_{t}, y_{t}\right)$. If the value is greater than 1 , it represents a positive TFP growth from $t$ to $t+1$. In fact, this index is the equal-proportion median of two Malmquist TFP indexes based on outputs. Further decomposition of the index can be obtained as follows:

$$
\mathrm{m}_{0}\left(y_{t+1}, x_{t+1}, y_{t}, x_{t}\right)=\frac{\mathrm{d}_{0}^{t+1}\left(x_{t+1}, y_{t+1}\right)}{d_{0}^{t}\left(x_{t}, y_{t}\right)} \times\left[\frac{d_{0}^{t}\left(x_{t+1}, y_{t+1}\right)}{d_{0}^{t+1}\left(x_{t+1}, y_{t+1}\right)} \times \frac{d_{0}^{t}\left(x_{t}, y_{t}\right)}{d_{0}^{t+1}\left(x_{t}, y_{t}\right)}\right]^{1 / 2}
$$

Moreover, the following relations exist in the above formula:

$$
\begin{gathered}
E F F C H=\frac{\mathrm{d}_{0}^{t+1}\left(x_{t+1}, y_{t+1}\right)}{\mathrm{d}_{0}^{t}\left(x_{t}, y_{t}\right)}, T E C H C H=\left[\frac{d_{0}^{t}\left(x_{t+1}, y_{t+1}\right)}{d_{0}^{t+1}\left(x_{t+1}, y_{t+1}\right)} \times \frac{d_{0}^{t}\left(x_{t}, y_{t}\right)}{d_{0}^{t+1}\left(x_{t}, y_{t}\right)}\right]^{1 / 2} \\
\text { Malmquist }=\text { TECHCH } \times \text { EFFCH } \\
\text { EFFCH }=\text { PECH } \times \text { SECH }
\end{gathered}
$$

Where, EFFCH represents the comprehensive technical efficiency change, TECHCH represents the technical progress change, $\mathrm{PECH}$ represents the pure technical efficiency change, SECH represents the scale efficiency change, and Malmquist or TFPCH, represents the total factor productivity index.

\section{B. Variables and descriptive statistics}

According to the relevant literature and theoretical analysis, this paper selected 2 input indicators and 5 output indicators, constructed panel data based on the Statistical Yearbook of Tibetan Areas in Sichuan, and analyzed poverty alleviation efficiency of 31 counties in Aba and Ganzi Prefectures from 2014 to 2016. In terms of input, fiscal poverty alleviation is measured by the annual public fiscal budget expenditure, and financial poverty alleviation is expressed by the annual loan balance of financial institutions. In terms of output, referring to previous literature and considering the effects of poverty alleviation from multiple dimensions, the following five indicators are selected: urbanization rate, GDP (per capita), private economic added value (per capita), total highway mileage and number of people employed in the first industry. The descriptive statistics of the main variables are shown in the "Table I" below: 
TABLE I. DESCRIPTIVE ANALYSIS OF VARIABLES

\begin{tabular}{c|l|l|l|l|l}
\hline Indicators & \multicolumn{1}{|c|}{ Variables } & \multicolumn{1}{c|}{ Mean } & \multicolumn{1}{c|}{ SD } & \multicolumn{1}{c|}{ Min } & \multicolumn{1}{c}{ Max } \\
\hline \multirow{2}{*}{$\begin{array}{c}\text { Input } \\
\text { Indicators }\end{array}$} & Financial input (public fiscal budget expenditure) & 126899.60 & 32793.83 & 74045.00 & 297126.00 \\
\cline { 2 - 7 } & Financial input (loan balance of financial institutions) & 148165.60 & 210053.90 & 7758.00 & 1317985.00 \\
\hline \multirow{4}{*}{$\begin{array}{c}\text { Output } \\
\text { Indicators }\end{array}$} & Urbanization rate & 30.18 & 10.14 & 13.62 & 52.38 \\
\cline { 2 - 7 } & GDP (per capita) & 22163.06 & 11159.18 & 7228.00 & 57277.00 \\
\cline { 2 - 7 } & Private economic added value (per capita) & 9743.70 & 5154.78 & 4041.00 & 29120.00 \\
\cline { 2 - 7 } & Total highway mileage & 1484.29 & 616.08 & 679.00 & 4894.00 \\
\cline { 2 - 7 } & Number of people employed in the first industry & 2.64 & 0.84 & 1.17 & 4.68 \\
\hline
\end{tabular}

\section{Comparison of efficiency between fiscal poverty alleviation and financial poverty alleviation}

1) Overall comparison: After running DEAP2.1 software, the fiscal and financial poverty alleviation efficiency of 31 counties in Tibetan areas of Sichuan from 2014 to 2016 can be obtained. Among them, the comprehensive technical efficiency $(\mathrm{EFFCH})$ reflects the poverty alleviation efficiency from an overall perspective. In terms of fiscal poverty alleviation, the mean of EFFCH of the 31 counties was 0.991 , indicating that the investment of poverty alleviation funds had played a considerable role on the whole, and only $0.9 \%$ of the investment had not taken effect of poverty alleviation. From a regional perspective, DEA efficiency is shown in most counties. In Aba Prefecture, Jinchuan County, Wenchuan County, Aba County, Mao County, Malcolm City and Li County all have EFFCH of 1.0 or above, accounting for about $46.15 \%$ of Aba Prefecture, and the EFFCH of the remaining 7 counties are all above 0.9. In Ganzi Prefecture, DEA efficiency is shown in about $55.56 \%$ of the counties, and there is an extremely high EFFCH in Shiqu county, Jiulong County, Kangding County, Huding County, Derong County, Daocheng County, Xiangcheng County, Danba County, Batang County and Dege County, indicating that the poverty alleviation measures for Tibetan areas in Sichuan has played a great role in recent years.

In "Table II", it is obvious that compared to the fiscal poverty alleviation, financial poverty alleviation is more efficient and the mean of EFFCH even reached 1.085. In terms of financial poverty alleviation, in Aba Prefecture, only DEA of Malcolm County is invalid, and the rest all reach 1.0 or above. In Ganzi Prefecture, there are also $66.67 \%$ of the counties realizing DEA efficiency. Thus, the credit incentive policies implemented for Tibetan areas in Sichuan in recent years have had a great effect on poverty alleviation. The innovative financial products such as the small credit for poverty alleviation, the agricultural loan through, the subsidized interest loan for poverty alleviation, and the guaranteed loan, have brought abundant capital to Tibetans. In Ganzi Prefecture, the Branch of CADB (Agricultural Development Bank of China) has signed strategic cooperation agreements on financial poverty alleviation with the governments of Kangding City, Shiqu County and Dege County, which is a starting point for Ganzi Prefecture's bank-government cooperation.

In addition, it can be found on a closer inspection that all the counties that fiscal poverty alleviation is effective also show effective financial poverty alleviation, which is closely related to the national poverty reduction policy. The CDB (China Development Bank) provides funding for Tibetan areas in Sichuan, and explore the mode of "fiscal funds + credit funds" to support poverty-stricken areas. On the basis of planning cooperation, the CDB will carry out a joint research poverty alleviation with Sichuan Province, to strengthen the coordination between financial policy and fiscal policy. Specifically, they will increase the funding support for the transportation network, infrastructure, industry development and people's livelihood projects. 
TABLE II. OVERALL COMPARISON OF EFFICIENCY BETWEEN FISCAL AND FINANCIAL POVERTY ALLEVIATION

\begin{tabular}{|c|c|c|c|c|c|c|c|}
\hline \multicolumn{4}{|c|}{ Fiscal Poverty Alleviation } & \multicolumn{4}{|c|}{ Financial Poverty Alleviation } \\
\hline Aba & EFFCH & Ganzi & EFFCH & Aba & EFFCH & Ganzi & EFFCH \\
\hline Jinchuan & 1.082 & Shiqu & 1.158 & Songpan & 1.342 & Shiqu & 1.637 \\
\hline Wenchuan & 1.036 & Jiulong & 1.117 & Heishui & 1.324 & Xiangcheng & 1.296 \\
\hline Aba & 1.003 & Kangding & 1.102 & Hongyuan & 1.254 & Seda & 1.211 \\
\hline Mao & 1.000 & Luding & 1.098 & Wenchuan & 1.235 & Yajiang & 1.194 \\
\hline Malcolm & 1.000 & Derong & 1.087 & Rangtang & 1.194 & Jiulong & 1.142 \\
\hline $\mathrm{Li}$ & 1.000 & Daocheng & 1.065 & $\mathrm{Li}$ & 1.169 & Luding & 1.123 \\
\hline Xiaojin & 0.991 & Xiangcheng & 1.027 & Xiaojin & 1.134 & Daofu & 1.054 \\
\hline Rangtang & 0.976 & Danba & 1.018 & Mao & 1.131 & Litang & 1.049 \\
\hline Jiuzhaigou & 0.962 & Batang & 1.006 & Jiuzhaigou & 1.128 & Luhuo & 1.041 \\
\hline$\underline{\text { Ruoergai }}$ & 0.955 & Dege & 1.000 & Aba & 1.097 & Danba & 1.002 \\
\hline Songpan & 0.940 & Baiyu & 0.992 & Ruoergai & 1.069 & Xinlong & 1.000 \\
\hline Hongyuan & 0.930 & Yajiang & 0.979 & Jinchuan & 1.065 & Dege & 1.000 \\
\hline \multirow[t]{6}{*}{ Heishui } & 0.925 & Xinlong & 0.950 & Malcolm & 0.886 & Daocheng & 0.980 \\
\hline & & Ganzi & 0.920 & & & Kangding & 0.976 \\
\hline & & Litang & 0.915 & & & Baiyu & 0.955 \\
\hline & & Luhuo & 0.910 & & & Ganzi & 0.896 \\
\hline & & Daofu & 0.875 & & & Batang & 0.882 \\
\hline & & Seda & 0.800 & & & Derong & 0.624 \\
\hline \multicolumn{2}{|l|}{ Mean } & \multicolumn{2}{|l|}{0.991} & \multicolumn{2}{|l|}{ Mean } & \multicolumn{2}{|l|}{1.085} \\
\hline
\end{tabular}

2) Vertical comparison: As the Malmquist index is a growth index, the results will not be available until the second phase. That is, the Malmquist TFP value will be set as 1 in 2014, and the poverty alleviation efficiency of subsequent years will be analyzed based on it. What should be noted is that, EFFCH $=\mathrm{PECH} * \mathrm{SECH}$, Malmquist $=\mathrm{EFFCH} * \mathrm{TECHCH}$.

In terms of EFFCH, it can be seen from "Table III" that in the past three years, both fiscal and financial poverty alleviation efficiency was relatively high, and financial poverty alleviation efficiency was slightly higher than fiscal poverty alleviation efficiency. In terms of fiscal poverty alleviation, from 2014 to 2015 , the EFFCH of Tibetan areas in Sichuan was 1.004, but from 2015 to 2016 , it decreased to 0.978 , which was mainly attributed to the decline of PECH. Although the SECH increased during this period, the increase was less than the decline of PECH. SECH reflects the governance of investment scale, while PECH reflects the efficiency and accuracy in the use and management of financial funds. This shows that although the government has achieved an appropriate investment scale, the specific use and structural allocation of financial funds need to be further improved. In terms of financial poverty alleviation, the efficiency of financial poverty alleviation has been improved in recent years.
Although the PECH has been reduced, financial institutions and credit departments have continuously expanded their credit supply to Tibetan areas in Sichuan and adopted a series of policies to relax credit access, which has greatly improved the SECH.

In terms of Malmquist, neither fiscal poverty alleviation nor financial poverty alleviation achieves DEA efficiency, but fiscal poverty alleviation efficiency is higher than financial poverty alleviation efficiency. In terms of fiscal poverty alleviation, from 2014 to 2016, the Malmquist has increased, and DEA was efficient from 2015 to 2016, which mainly thanks to the rapid technological progress. Though the EFFCH declined, but the government's policy on the use of fiscal funds constantly optimized, making the Malmquist improved. From the perspective of financial poverty alleviation, its Malmquist has declined, which is caused by the slight improvement of EFFCH and the sharp decline of TECHCH. This indicates that although the credit input has been increasing in recent years, the application of credit funds is not mature enough, and it has been difficult to achieve substantial improvement. The Tibetan areas in Sichuan have been lifted out of poverty in an all-round way, but if we want to achieve sustainable poverty 
reduction through credit, we still need to constantly

optimize the credit ratio and capital utilization strategy.

TABLE III. VERTICAL COMPARISON OF EFFICIENCY BETWEEN FISCAL AND FINANCIAL POVERTY ALLEVIATION

\begin{tabular}{c|l|l|l|l|l|l|l|l|l|l}
\hline & \multicolumn{4}{|c|}{ Fiscal Poverty Alleviation } & \multicolumn{5}{c}{ Financial Poverty Alleviation } \\
\hline Year & EFFCH & TECHCH & PECH & SECH & Malmquist & EFFCH & TECHCH & PECH & SECH & Malmquist \\
\hline $\mathbf{2 0 1 4 - 2 0 1 5}$ & 1.004 & 0.856 & 0.996 & 1.009 & 0.860 & 0.997 & 0.952 & 1.107 & 0.901 & 0.949 \\
\hline $\mathbf{2 0 1 5 - 2 0 1 6}$ & 0.978 & 1.031 & 0.967 & 1.012 & 1.009 & 1.180 & 0.744 & 1.052 & 1.122 & 0.878 \\
\hline Mean & 0.991 & 0.94 & 0.981 & 1.011 & 0.932 & 1.085 & 0.842 & 1.079 & 1.005 & 0.913 \\
\hline
\end{tabular}

3) Horizontal comparison: In order to further compare the efficiency of poverty alleviation in various counties of Tibetan areas in Sichuan, according to the EFFCH, "Fig. 1" was drawn with the effective value 1 of DEA as the critical point. This figure shows the poverty alleviation effects in Aba and Ganzi Prefectures from 2014 to 2016, and is divided into four parts, that is, mature type (the first quadrant), financial type (second quadrant), backward type (the third quadrant) and fiscal type (the fourth quadrant).

In the first quadrant (mature type), as mentioned in the overall comparison, many counties with high efficiency of fiscal poverty alleviation also has high financial poverty alleviation efficiency, mainly including Luding County, Jiulong County, Aba County, Xiangcheng County, Wenchuan County and Jinchuan County. These counties were influenced by the "fiscal + financial" policy for poverty alleviation, which makes that the fiscal funds and loans have a significant role in poverty reduction, and the efficiency is relatively high. In the second quadrant (financial type), these areas mainly have a high efficiency of financial poverty alleviation but a low efficiency of fiscal poverty alleviation, mainly including Seda County, Heishui County, Hongyuan County, Songpan County, Rangtang County, Yajiang County, Jiuzhaigou County, Daofu County, Litang County, Luhuo County, Mao County and Ruoergai County. These areas need to adjust the fiscal strategy to improve the efficiency of fiscal poverty alleviation. In the third quadrant (backward type), the efficiency of fiscal and financial poverty alleviation in these areas is relatively low, including Baiyu County and Ganzi County. In the rural revitalization stage, for these areas, it is necessary to constantly improve the efficiency of fund utilization apart from ensuring the investment of funds. In the fourth quadrant (fiscal type), these areas have a high efficiency of fiscal poverty alleviation but a low efficiency of financial poverty alleviation. In the postpoverty alleviation era, where the market-oriented means for poverty alleviation are valued, more attention should be paid to the improvement of financial poverty alleviation efficiency. In addition, there are many counties located on the axis, which achieve DEA efficiency in both fiscal and financial poverty alleviation.

In general, the two means of poverty alleviation interact and complement each other, and have a synergistic effect to a certain extent to jointly promote the poverty alleviation and further improvement of economic development in Tibetan areas of Sichuan. Additionally, relatively speaking, the efficiency of financial poverty alleviation is higher than that of fiscal poverty alleviation. 


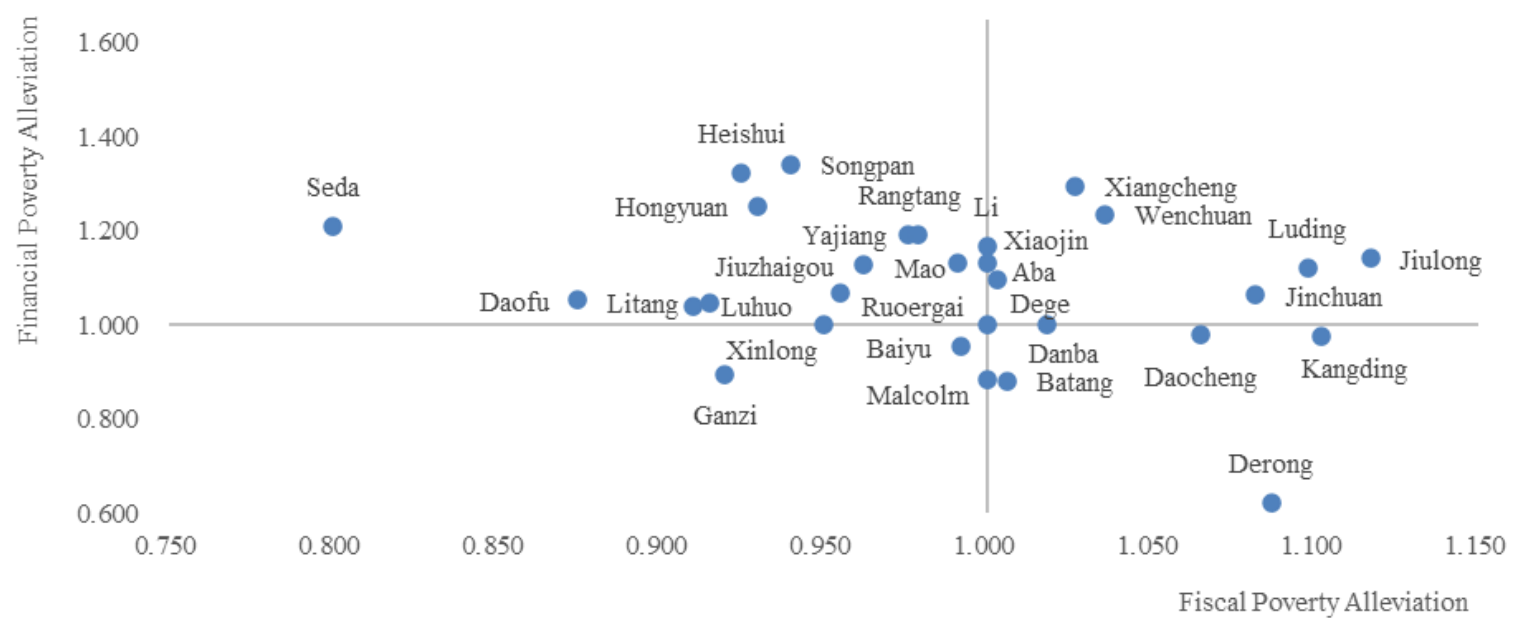

Fig. 1. Horizontal comparison of efficiency between fiscal and financial poverty alleviation.

\section{CONClUSiON}

In order to provide practical advices for the formulation of poverty alleviation policies, the efficiency of fiscal poverty alleviation and financial poverty alleviation was compared in this paper. Based on the Statistical Yearbook of Tibetan Areas in Sichuan from 2014 to 2016, this paper used the DEA-Malmquist index model to calculate the fiscal and financial poverty alleviation efficiency of 31 counties in Aba and Ganzi Prefectures. Then, comparisons from the overall, horizontal and vertical aspects were made. Finally, it can be found that the efficiency of financial poverty alleviation is higher than that of fiscal poverty alleviation from any point of view. Based on the above conclusions, this paper proposes the following policy recommendations:

Firstly, fiscal funds for poverty alleviation should be invested continuously, but the efficiency of capital allocation should be improved. In the post-poverty alleviation era, the government's role should be weakened gradually, the dependence of the Tibetans to fiscal subsidies must be reduced, but the sudden withdrawal of fiscal input is also not permitted. At the same time, the government should continue to input fiscal poverty-alleviation funds, but need to allocate the funds rationally and improve the efficiency of capital operation according to the production condition and business capacity of the Tibetans.

Secondly, the focus should be shifted to the financial poverty alleviation represented by credit poverty alleviation, and the construction and development of financial institutions should also be paid attention to. As a market-oriented means of poverty alleviation, credit plays an important role in promoting the endogenous driving force of Tibetans and realizing sustainable poverty reduction. However, at present, the rural financial service system in Tibetan areas is not perfect, and the monopoly of rural credit cooperatives is very common. Therefore, the government should play a macro-control role and rationally deploy the construction of rural financial institutions.

Thirdly, the credit service products should be innovated to realize the match of financial supply and demand, and improve the efficiency of financial poverty alleviation. Subject to the requirements on loan collaterals in formal financial institutions, the poor households in Tibetan areas often find it difficult to meet a series of credit conditions of financial institutions. Financial institutions should have an indepth understanding of financial needs of Tibetans, to design reasonable and effective innovative financial products according to Tibetan characteristics, build information sharing platform using cloud technology, strengthen the popularization of credit policies and credit knowledge, and realize the matching of credit supply and demand.

\section{Acknowledgment}

This paper is acknowledged by the research interest cultivation program of Sichuan Agricultural University "Research on Long-term Mechanism of Sustainable Credit Poverty Reduction in Tibetan Areas of Sichuan (2020432)".

\section{References}

[1] Wen T., Wang Y., Study on the Effectiveness of Agricultural Loans and Financial Support for Agriculture on Farmers' Income Growth[J]. Research on Financial and Economic Issues,2005(02):78-83.

[2] Jia J., Qin C., Liu Y., Policy Design Integrating "top-down" and "bottom-up" — Based on Experience Analysis of Rural 
Development Poverty Alleviation Projects[J]. Chinese Social Science,2017(09): 68-89+206-207.

[3] Shen Y., Chen J., Comparative Study on Fiscal Poverty Alleviation and Financial Poverty Alleviation Efficiency[J]. Rural Finance Research,2020(01):27-36.

[4] Wu B., Ge Y., Ma J., Performance Comparison between Fiscal Poverty Alleviation and Financial Poverty Alleviation in the Period of Targeted Poverty Alleviation: From the Perspective of Heterogeneity of Poverty Alleviation and Multidimensional Poverty[J]. China Rural Economy,2019(07):21-36.

[5] Farerr, Grosskopfs, Norrism. Productivity Growth, Technical Progress, and Efficiency Change in Industrialized Countries[J]. American Economic Review,1994,84(1): 66-83.

[6] Jalilian H.,Kirkpatrick C. Financial Development and Poverty Reduction in Developing Countries[J]. International Journal of Finance \& Economics,2002, 7(2): 97-108

[7] Selim Akhter, Kevin J. Daly. Finance and poverty: Evidence from fixed effect vector decomposition[J]. Emerging Markets Review,2009,10(3): 191-206

[8] Greenwood J., and B.Jovanovic, Financial Development, Growth, and the Distribution of Income[J]. Journal of Political Economy, 1990, 98(5): 1076-1107 